\title{
\begin{tabular}{l|l} 
MitTraries & DSpace@MIT
\end{tabular}
}

\author{
MIT Open Access Articles
}

The unexpected surface of asteroid (101955) Bennu

The MIT Faculty has made this article openly available. Please share how this access benefits you. Your story matters.

Citation: Lauretta, D.S., et al., "The unexpected surface of asteroid (101955) Bennu." Nature 568, 7750 (March 2019): p. 55-60 doi 10.1038/s41586-019-1033-6 (c)2019 Author(s)

As Published: 10.1038/s41586-019-1033-6

Publisher: Springer Science and Business Media LLC

Persistent URL: https://hdl.handle.net/1721.1/124687

Version: Author's final manuscript: final author's manuscript post peer review, without publisher's formatting or copy editing

Terms of use: Creative Commons Attribution-Noncommercial-Share Alike 
Published in final edited form as:

Nature. 2019 April ; 568(7750): 55-60. doi:10.1038/s41586-019-1033-6.

\section{The Unexpected Surface of Asteroid (101955) Bennu}

Users may view, print, copy, and download text and data-mine the content in such documents, for the purposes of academic research, subject always to the full Conditions of use:http://www.nature.com/authors/editorial_policies/license.html\#terms

Correspondence and requests for materials and reprints should be directed to Dante S. Lauretta (lauretta@orex.lpl.arizona.edu).

$\dagger$ These authors contributed equally to this work.

Author contributions

D.S.L. led the OSIRIS-REx mission, analysis, and writing of the paper. D.N.G. leads the Image Processing Working Group (IPWG) including C.A.B., D.R.G, K.B., T.L.B., H.C., E.S.H., and P.H.S. The IPWG developed the image calibration pipeline, produced the global mosaic, analyzed the surface for albedo variations, and calculated the relative reflectance in the different MapCam filters. O.S.B. led the altimetry investigation and produced the elevation data. W.F.B. performed dynamical analysis linking Bennu to dark asteroids in the main asteroid belt. S.S.B.-K., W.V.B., B.E.C., C.D.d'A., H.L.E., C.W.H., M.C.N., and B.R. designed the observation profiles and OCAMS operations plans for mission design and data acquisition. C.W.H. also led the astronomical characterization. H.C.C. Jr., J.P.D., and C.W.V.W. contributed substantially to the content and writing of the manuscript. J.P.E. led the thermal analysis V.E.H. led the spectral analysis and M.R.M.I and H.H.K. led the characterization and interpretation of the magnetite visible spectral properties. H.L.R. led the graphic design and figure development. D.J.S. led the radio science analysis. and K.J.W. led the geologic investigation of Bennu. The entire OSIRIS-REx Team made the encounter with Bennu possible.

The authors declare no financial or non-financial competing interests.

Full list of the OSIRIS-REx Team:

C. Adam, M. Al Asad, B. Allen, P. Antreasian, S. Anwar, J. Aponte, A. Aqueche, B. Ashman, E. Asphaug, E. Audi, J. Backer, R. Ballouz, J. Bandfield, M. Barker, O. Barnouin, A. Bartels, A. Barucci, J. Bauman, J. Bayron, K. Becker, T. Becker, C. Beddingfield, K. Bellamy, J. Bellerose, S. Bendall, C. Bennett, K. Berry, S. Bhaskaran, B. Bierhaus, O. Billett, R. Binzel, P. Bland, H. Bloomenthal, L. Bloomquist, D. Blum, A. Boggs, N. Bojorquez-Murphy, B. Bos, W. Bottke, H. Bowles, N. Bowles, C. Boyles, W. Boynton, D. Brack, L. Breitenfeld, J. Brodbeck, E. Brown, J. Brucato, C. Brunet, C. Bryan, B. Buck, K. Burke, R. Burns, A. Burton, A. Calloway, H. Campins, M. Caplinger, B. Carcich, S. Carlson-Kelly, R. Carpenter, S. Carter, N. Castro, J. Cerna, K. Chaffin, W. Chang, S. Chesley, A. Cheuvront, R. A. Chicoine, M. Chodas, M. Chojnacki, P. Christensen, E. Church, B. Clark, B. Clark, S. Clemett, E. Cloutis, M. Coltrin, H. Connolly, J. Contreras, M. Corvin, R. Cosentino, K. Craft, K. Crombie, J. Cutts, J. Daly, M. Daly, C. d'Aubigny, J. de Leon, D. Dean, A. Deguzman, M. Delbo, D. DellaGiustina, J. D. P. Deshapriya, S. Desjardins, B. Diallo, S Dickenshied, C. Dickinson, K. Dill, D. Doerres, K. Donaldson Hanna, E. Dotto, D. Drinnon, K. Drozd, R. Dubisher, J. Dworkin, D. Eckart, K. Edmundson, C. Elder, J. Elsila Cook, J. Emery, C. Emr, H. Enos, R. Enos, C. Ernst, R. Espiritu, D. Everett, P. Falkenstern, D. Farnocchia, C. Fellows, D. Fennell, Y. Fernandez, T. Ferro, S. Ferrone, A. Fisher, M. Fisher, M. Fisher, T. Fisher, G. Fitzgibbon, M Fitzgibbon, P. Fleming, K. Fleshman, D. Folta, J. Forelli, S. Fornasier, T. Forrester, K. Fortney, I. Franchi, S. Francis, J. Freemantle, A French, S. Freund, M. Fulchignoni, I. Galinsky, R. Garcia, A. Gardner, S. Gardner, J. Garvin, R. Gaskell, D. Gaudreau, J. Geeraert, K. Getzandanner, R. Ghent, M. Giuntini, D. Glavin, T. Glotch, D. Golish, S. Gonzales, N. Gorius, J. Grindlay, J. Grossman, D. Guevel, P. Haas, C. Haberle, N. Habib, W. Hagee, T. Haltigin, D. Hamara, V. Hamilton, D. Hammond, R. Hanna, A. Harbison, A. Harch, K. Harshman, C. Hartzell, P. Hasselmann, P. Hayne, C. Hergenrother, D. Highsmith, A. Hilbert, A. Hildebrand, D. Hill, J. Hill, D. Hoak, C. Hoekenga, J. Hoffman, M. Holdridge, J. Hong, S. Hooven, D. Howell, E. Howell, E. Huettner, S. Hull, K. Hyde, H. Ido, A. Ingegneri, T. Ireland, M. Izawa, F. Jaen, E. Jawin, N. Jayakody, M. Jenkins, C. Johnson, G. Johnston, J. Jones, M. Jones, N. Jones, J. Joseph, P. Kaotira, H. Kaplan, T. Kareta, E. Keates, L. Keller, B. Kennedy, B. Key, J. Kidd, A. Knight, S. Balram-Knutson, L. Koelbel, J. Kreiner, D. Kubitschek, D. Lambert, M. Lambert, C. Lantz, D. Lauretta, L. Le Corre, M. Lefevre, J. Leonard, E. Lessac-Chenen, A. Levine, C. Lewin, J.-Y. Li, J. Liang, G. Libourel, J. Licandro, L. Lim, A. Liounis, C. Lorentson, D. Lorenz, B. Lovelace, M. Loveridge, M. Lujan, A. Lunsford, J. Lyzhoft, H. Ma, C. Maleszewski, R. Malhotra, J. Mapel, K. Marchese, C. Mario, J. Marshall, K. Martin, N. Martinez-Vlasoff, B. Marty, R. Masterson, N. Mastrodemos, C. May, E. Mazarico, E. Mazzotta Epifani, J. McAdams, L. McCarthy, T. McCoy, E. McDonough, T. McElrath, M. McGee, L. McGraw, J. McMahon, L. McNamara, G. Mehall, F. Merlin, S. Messenger, P. Michel, M. Milazzo, C. Miller, G. Miller, S. Millington-Veloza, M. Miner, R. Mink, A. Mirfakhrai, N. Mogk, J. Molaro, W. Moore, M. Moreau, M. Morris, V. Morrison, E. Morton, E. Muhle, S. Mullen, R. Munoz, J. Nagy, H. Nair, K. NakamuraMessenger, D. Nelson, J. Nelson, G. Neumann, A. Nguyen, L. Nguyen, V. Nifo, M. Nolan, C. Norman, D. Noss, J. Nuth, R. Olds, S. Oliver, W. Owen, B. Page, M. Pajola, E. Palmer, C. Parish, R. Park, D. Patterson, J. Peachey, J. Pelgrift, R. Pennington, M. Perry, L. Philpott, N. Piacentine, J. Plescia, G. Poggiali, D. Poland, A. Polit, A. Praet, E. Queen, N. Ramos, M. Rascon, V. Reddy, D. Reuter, L. Rhoads, D. Richardson, S. Rieger, K. Righter, K. Rios, B. Rizk, J. L. Rizos Garcia, J. Roberts, D. Rogers, H. Roper, D. Rowlands, B. Rozitis, A. Rubi, B. Rush, S. Russell, A. Ryan, M. Ryle, E. Sahr, S. Salazar, D. Sallitt, S. Sandford, D. Scheeres, M. Schmitzer, D. Schrader, S. Schwartz, J. Seabrook, S. Selznick, G. Shaw, P. Sherman, N. Shultz, S. Sides, M. Siegler, A. Simon, M. Skeen, J. Small, M. Smith, P. Smith, S. Squyres, K. Stakkestad, D. Stanbridge, R. Steele, J. Stromberg, M. Susak, H. Susorney, B. Sutter, S. Sutton, L. Swanson, J. Swenson, T. Swindle, S. Tachibana, K. Tait, Y. Takahashi, A. Taylor, F. Teti, C. Thayer, C. Thomas, Kathie ThomasKeprta, F. Thuillet, A. Toland, Q. Tran, D. Trang, P. Tricarico, R. Turner, P. Vasudeva, D. Vaughan, D. Velez, D. Vokrouhlicky, K. Walsh, S.-i. Watanabe, J. Weirich, C. Welch, J. Wendel, M. Westermann, D. Wibben, B. Williams, K. Williams, R. Witherspoon, P. Wolff, C. Wolner, J. Wood, D. Worden, P. Wren, B. Wright, K. Yetter, M. Yoshikawa, H. Yurimoto, J. Zareski, T. Zega, R. Zellar, Z. Zeszut, X.-D. Zou 
D. S. Lauretta ${ }^{1, \dagger}$, D. N. DellaGiustina ${ }^{1}, \dagger$, C. A. Bennett ${ }^{1}$, D. R. Golish ${ }^{1}$, K. Becker ${ }^{1}$, S. S. Balram-Knutson $^{1}$, O. S. Barnouin ${ }^{2}$, T. L. Becker ${ }^{1}$, W. F. Bottke ${ }^{3}$, W. V. Boynton ${ }^{1}$, H. Campins $^{4}$, B. E. Clark ${ }^{5}$, H. C. Connolly Jr. ${ }^{6}$, C. Drouet d'Aubigny ${ }^{1}$, J. P. Dworkin ${ }^{7}$, J. P. Emery $^{8}$, H. L. Enos ${ }^{1}$, V. E. Hamilton ${ }^{3}$, C. W. Hergenrother ${ }^{1}$, E. S. Howell ${ }^{1}$, M. R. M. Izawa ${ }^{9}$, H. H. Kaplan ${ }^{3}$, M. C. Nolan ${ }^{1}$, B. Rizk ${ }^{1}$, H. L. Roper ${ }^{1}$, D. J. Scheeres ${ }^{10}$, P. H. Smith ${ }^{1}$, K. J. Walsh ${ }^{3}$, C. W. V. WoIner ${ }^{1}$, and OSIRIS-REx Team

${ }^{1}$ Lunar and Planetary Laboratory, University of Arizona, $1415 \mathrm{~N}$ 6th Ave, Tucson, AZ 85705, USA.

${ }^{2}$ The Johns Hopkins University Applied Physics Laboratory, 11100 Johns Hopkins Road, Laurel, MD 20723, USA.

${ }^{3}$ Southwest Research Institute, 1050 Walnut St Suite 300, Boulder, CO 80302, USA.

${ }^{4}$ Department of Physics, University of Central Florida, Orlando, FL 32816, USA.

${ }^{5}$ Department of Physics and Astronomy, Ithaca College, Ithaca, NY 14850, USA.

${ }^{6}$ Department of Geology, Rowan University, Glassboro, NJ 08028, USA.

${ }^{7}$ NASA Goddard Space Flight Center, Greenbelt, MD 20771, USA.

${ }^{8}$ Department of Earth and Planetary Sciences, University of Tennessee, Knoxville, TN 37996, USA.

${ }^{9}$ Institute for Planetary Materials, Okayama University-Misasa, 827 Yamada, Misasa, Tottori 682-0193, Japan.

${ }^{10}$ Smead Department of Aerospace Engineering, University of Colorado, Boulder, CO 80309, USA.

\section{Abstract}

NASA'S Origins, Spectral Interpretation, Resource Identification, and Security-Regolith Explorer (OSIRIS-REx) spacecraft recently arrived at near-Earth asteroid (101955) Bennu, a primitive body that represents the objects that may have brought prebiotic molecules and volatiles such as water to Earth [1]. Bennu is a low-albedo B-type asteroid [2] that has been linked to organic-rich hydrated carbonaceous chondrites [3]. Such meteorites are altered by ejection from their parent body and contaminated by atmospheric entry and terrestrial microbes. Thus, the primary mission objective is to return a sample of Bennu to Earth that is pristine, i.e., not affected by these processes [4]. The OSIRIS-REx spacecraft carries a sophisticated suite of instruments to characterize Bennu's global properties; support selection of a sampling site; and document that site at sub-centimeter scales [5-11]. Here we consider early observations to understand how Bennu's properties compare to pre-encounter expectations and the prospects for sample return. The bulk composition of Bennu appears to be hydrated and volatile-rich, as expected. However, in contrast to pre-encounter modeling of Bennu's thermal inertia [12] and radar polarization ratios [13] — which indicated a generally smooth surface covered by centimeter-scale particles—resolved imaging reveals an unexpected surficial diversity. The albedo, texture, particle size, and roughness are beyond the spacecraft design specifications. On the basis of our pre-encounter knowledge, we developed a sampling strategy to target 50-m-diameter patches of loose regolith with grain sizes less than $2 \mathrm{~cm}$ [4]. We observe only a small number of apparently hazard-free regions, on the order of 5 to 20 meters in extent, the sampling of which poses a substantial challenge to mission success. 
Measurements from the OSIRIS-REx spacecraft's approach to and initial survey of Bennu identified spectral features; constrained the shape, rotation period, and mass; characterized the photometric properties; described the global thermal inertia; and revealed the surficial characteristics of the asteroid. These data allow us to evaluate the Design Reference Asteroid (DRA), a document we created to inform mission design based on telescopic observations [14]. The DRA "scorecard" (Table 1) tracks how our pre-encounter knowledge matches reality.

Bennu's global properties largely match those determined by the pre-encounter astronomical campaign. In disk-integrated observations, the visible-to-near-infrared spectrum has a blue (negative) slope [15], confirming the B-type taxonomy. At longer wavelengths, a 2.7- $\mu \mathrm{m}$ spectral absorption band is present, consistent with the presence of hydrated silicates. Thermal emission spectra are similar to those of CM carbonaceous chondrites and contain a spectral feature at $23 \mu \mathrm{m}$, also consistent with phyllosilicates. Thus, OSIRIS-REx spectral data support the affinity with hydrated carbonaceous chondrites indicated by ground-based observations [3].

Bennu's physical properties are also consistent with findings from the astronomical campaign (Table 1). Bennu exhibits the expected spinning-top shape [16], and its rotation period, obliquity, and rotation pole are within the 1-sigma uncertainties of the ground-based values. The shape and topography indicate low levels of internal shear strength or cohesion. A mass determination from radio science [17] yields a density of $1190 \pm 13 \mathrm{~kg} / \mathrm{m}^{3}$. The low density of Bennu is consistent with a rubble-pile structure containing 50\% macroporosity, assuming a particle density characteristic of the $\mathrm{CM}$ chondrites. Bennu thus appears to be a microgravity aggregate.

At 100 million to 1 billion years old, Bennu's surface is older than expected based on dynamical models of rubble-pile evolution, but shows overprinting from more recent activity [18]. High-standing, north-south ridges extend from pole to pole [16], dominating the topography and apparently directing the flow of surface material. Recent surface processes are evident in the deficiency of small craters, infill of large craters, and surface mass wasting $[16,18]$. Fractured boulders have morphologies that suggest the influence of impact or thermal processes.

Measurements by the OSIRIS-REx Camera Suite (OCAMS) confirm that Bennu is one of the darkest objects in the Solar System, with a global geometric albedo of 4.4\% [19,20]. This finding is in agreement with pre-encounter measurements [2] and consistent with the CI and $\mathrm{CM}$ chondrites [3].

However, Bennu's surface displays an unexpected degree of albedo heterogeneity (Figure 1). The ratio of reflected-to-incident flux (I/F) of Bennu's surface at a solar phase angle of $0^{\circ}$ (Figure 1a) ranges from $3.5 \pm 0.2 \%$ in the dark regions (Figure $1 \mathrm{~b}$ ) to a maximum of $\geq 15 \%$ within discrete 2- to 3-m boulders (Figure 1e). The majority of large (>=30 $\mathrm{m}$ ) boulders have an albedo similar to the global average (Figure 1c). This wide range of albedo may confound the spacecraft guidance lidar system, requiring reassessment of the approach to sample site targeting [4]. 
The darkest material is concentrated in a large outcrop in Bennu's southern $(-Z)$ hemisphere (Figure 2), and in a subset of boulders perched on the surface (Figure 1b). Such material is also present in diffuse blanketing units that are not linked to distinct morphometric features [19]. Some instances show a spectral absorption at $0.55 \mu \mathrm{m}$, which has not previously been reported for any dark asteroid [21]. Magnetite $\left(\mathrm{Fe}_{3} \mathrm{O}_{4}\right)$ is the most likely source of this spectral feature [22]. This interpretation is consistent with the emissivity spectra obtained by the OTES instrument, which show features at $18 \mu \mathrm{m}$ and $29 \mu \mathrm{m}$ that may be due to magnetite [15].

The detection of magnetite on the surface of Bennu supports an affinity with both the CI and some (rare) CM chondrites [23, 24]. Magnetite in these meteorites is thought to be the product of aqueous alteration within a parent asteroid [25]. If so, then the darker regions of Bennu, where magnetite appears to be concentrated, may be fresher material than the brighter regions. This interpretation is consistent with some studies of space weathering of carbonaceous material [26]. However, other studies that simulated micrometeorite impactinduced alteration of the Murchison CM chondrite [27] produced slight darkening and nearsurface nanoparticulate sulfides and magnetite. The magnetite-bearing dark regions on Bennu therefore may consist of CM-like material that was altered during exposure to the space environment. The relationship between the duration of space exposure and albedo thus has several possible explanations.

The albedo variation on Bennu offers some insight into this relationship. Some boulders contain clasts that appear to be bound together with a darker matrix material (Figure 1d). These clastic rocks likely formed during impacts [18], which are known to produce regolith breccias [28]. In our initial census, we see albedo variation as high as $\sim 33 \%$ within the face of a single such boulder (Figure 1d). This finding suggests that the relative brightness of the individual clasts is not a product of space weathering. Instead, they likely represent distinct lithologies. Elsewhere, isolated boulders occur with similar albedos and sizes to the clastic material [19]. These boulders may be clasts that disaggregated from breccias through mechanical weathering processes, possibly thermally induced [29]. As these rocks break down, the interclastic matrix may separate and produce fine-particulate regolith. Spatially resolved global and regional spectral mapping of Bennu's surface by OSIRIS-REx will further constrain Bennu's composition, but ultimately, resolution of the questions raised by our early results relies on the successful acquisition and return of a sample. That task looks more challenging than we expected.

OTES measurements confirm the thermal inertia measured from the ground [19], which was interpreted as evidence of regolith particles averaging less than $1 \mathrm{~cm} \mathrm{[12].} \mathrm{However,} \mathrm{high-}$ resolution data obtained by OCAMS reveal the surface to be much rougher, with the largest boulder being $58 \mathrm{~m}$ across, more than 200 boulders $\geq 10 \mathrm{~m}$ present on the surface [19], and many more boulders evident at meter scales (Table 1; Figure 3a). This result should prompt a reassessment of the nature of asteroid surfaces as determined from thermal analysis [12, 30] and from radar circular polarization ratios [13], which suggested that Bennu's surface was smooth at the scale of the shortest radar wavelength $(3.5 \mathrm{~cm})$ with only one $10-$ to $20-\mathrm{m}$ boulder on the surface. As the OSIRIS-REx mission collects more data, we will be better 
able to define the relationship between thermal inertia, regolith, and boulder distribution, guiding sample site selection and future astronomical studies of asteroids.

Bennu's shape provided additional surprises. The most prominent feature in the radar shape model [13] is a pronounced equatorial ridge. Bennu's actual equatorial ridge is muted and, even though it has a larger radius on average than the rest of the asteroid, it has only isolated topographic high points [16]. This structure appears to have been substantially eroded by impacts, leaving only small residual outcrops.

The pre-encounter predicted distribution of slopes on Bennu led us to expect a subdued topography with loose material migrating into geopotential lows [31]. Near-infrared spectroscopy detected a positive spectral slope corresponding to sub-Earth latitudes nearest to the equator, with the implication that this region is dominated by fine-grained material [32]. We thus hypothesized that, over time, gravel migration had built up the equatorial ridge apparent in the radar shape model [1]. Even though the equatorial region is the geopotential low, it is in fact dominated by large concentrations of boulders with little apparent finegrained regolith (Figure 3a).

Bennu does not contain the extensive patches of fine-grained regolith to which we designed the mission [4]. However, we identified several areas, ranging from 5 to $20 \mathrm{~m}$ in extent, which appear relatively free of spacecraft hazards and have textures suggestive of abundant fine particles (Figure 3). Several are associated with regions of high slope (Figure 3b). Some of these sites are at the bottom of small craters (Figure 3c). Some are ringed by meter-scale rocks (Figure 3d). Others appear as slight depressions filled with darker fine-grained material (Figure 3e). The high-slope regions appear promising for sample acquisition because they span the largest spatial extent.

The upcoming OSIRIS-REx site selection campaign will provide spectroscopic and spectrophotometric measurements that will refine our understanding of surface reflectance, mineralogical distributions, geology, and thermal characteristics to complete the global assessment of the asteroid. We will select two sites, primary and backup, for detailed reconnaissance to determine if the particles in these areas are sampleable by the spacecraft. Regardless of the final site selected, the requirement for guidance, navigation, and control accuracy needs to be tightened.

Bennu's unexpected nature continues to reveal itself. In January 2019, after the spacecraft's insertion into orbit around Bennu, optical navigation images detected apparent particles in the vicinity of the asteroid [20,33]. This unexpected phenomenon is under investigation. We will perform a thorough safety assessment of the asteroid environment and all potential sample sites before committing the spacecraft to descend to the surface. Although we face a reality that differs from many of our predictions, we will attempt to sample Bennu before the spacecraft departs for Earth.

\section{Methods}

The figures presented in this manuscript are derived from OCAMS observations during the Approach and Preliminary Survey phases of the OSIRIS-REx mission [4]. The first section 
of the methods presents details of the image processing used to create the products in Figures 1 to 3 . The subsequent sections provide details on the observing profiles that were implemented to obtain the data products. The methods for determining the relationship between boulder size and normal albedo and for generating the global mosaic are included in a companion paper [19].

The data analysis methods for the parameters listed in Table 1 are provided in the other manuscripts in this package [15-20].

\section{Image processing}

Color images and broadband filter photometry-We generate the OCAMSMapCam global average spectrum shown in Figure 2 from images acquired on 8 and 9 November 2018, with a pixel scale of $\sim 11 \mathrm{~m} /$ pixel. MapCam acquired a set of color images, one image with each filter, on each day. We register the images manually in the U.S. Geological Survey's ISIS3 software to align the image data to their geometric backplanes. Pixels with a raw signal (measured in DN) outside of the linear regime of the OCAMS detectors $(1000-14000 \mathrm{DN})$ are scrubbed from the images. Any pixel that is scrubbed in one filter is scrubbed in all filters, such that a consistent subset of the surface is analyzed in all colors. The median reflectance of the remaining pixels is calculated for each filter.

To obtain the spectrum of the dark material from the 8 November images, we combine coregistered MapCam frames into a color cube that includes the $\mathrm{b}^{\prime}, \mathrm{v}, \mathrm{w}$, and $\mathrm{x}$ bands. The color cube is visualized by assigning the $\mathrm{w}, \mathrm{v}$, and $\mathrm{b}^{\prime}$ frames into RGB color channels. We select a $4 \times 5$ pixel rectangular polygon that encloses the dark spot in the RGB frame using the ISIS3 spectral plot tool. This determines the average I/F value of each band within the polygon. Values are then photometrically corrected based on their observation conditions.

To contrast these data with laboratory reflectance spectra of magnetite, we apply a correction to 30 degrees phase angle (see Reflectance distribution section below). Magnetite is a common phase in aqueously altered carbonaceous chondrites. Reflectance spectra of magnetite contain a local minimum near 0.55 microns wavelength and a blue overall spectral slope on the region from 0.4 to 1.0 microns. Figure 2 provides a comparison of the MapCam spectrum of Bennu's dark outcrop with the MAG105 reflectance spectrum presented in Figure $7 \mathrm{~b}$ of [22], which was found to be a good match with our data. This comparison is conducted by sampling the MAG105 spectrum at the effective wavelengths of the MapCam color bands and then shifting the spectrum linearly into the reflectance range of Bennu's surface (linearly reduced by -0.031292095 , which is the difference between the reflectance of MAG105 and Bennu's dark outcrop in the b' band). Subsequently, the spectra of Bennu's dark outcrop as well as the resampled and reduced MAG105 sample are divided by Bennu's global average spectrum in order to assess the relative reflectance of Bennu's dark outcrop and MAG105. Pure magnetite provides a qualitative spectral match to Bennu's dark material particularly in the $b, v$, and $w$ bands. The $x$ band reflectance of the Bennu dark outcrop is higher than that of pure magnetite; however, we emphasize that the dark outcrop is unlikely to be a single phase and has an unknown grain size, therefore an exact correspondence should not be expected. Nevertheless, the MapCam multispectral data are consistent with a 
major contribution from magnetite, which is consistent with plausible magnetite-related features observed by OTES [15].

Reflectance distribution-We generate the reflectance (I/F) distribution in Figure 1 by analyzing a global mosaic of Bennu, shown in Extended Data Figure 1. To create the mosaic, we project image data taken on 25 November 2018 with a pixel scale of $\sim 1.2 \mathrm{~m} /$ pixel into a sinusoidal map project, which preserves area, such that statistics performed on the mosaic can be interpreted as a function of area. We photometrically correct the image data to standard conditions (phase $30^{\circ}$, emission $0^{\circ}$, incidence $30^{\circ}$ ) for ease of comparison to meteorite analogs. We also calculate the normal albedo (phase $0^{\circ}$, emission $0^{\circ}$, incidence $0^{\circ}$ ) which is approximately equivalent to geometric albedo for low-reflectance objects such as Bennu. Emission and incidence angles are corrected to the desired conditions using a Lommel-Seeliger disk function and phase angles are corrected using an exponential phase function ( $\mathrm{Li}$ et al., 2015). For the correction to $0^{\circ}$ phase angle an additional step is performed. As the exponential phase curve used in our model does not have a term to account for the opposition surge, we perform a linear extrapolation from $2^{\circ}$ to $0^{\circ}$ phase angle as these data show a change in slope which departs from the best-fit exponential function. The resulting histogram of the mosaic (Figure 1) represents the I/F distribution across Bennu's surface, in terms of surface area. Shadowed areas are removed by calculating Sun-occluded terrain using ray tracing schemes implemented in ISIS3 [34] and the shape model of Bennu, and subsequently nulling those areas so that they are omitted from the final distribution.

We calculate the normal albedo variation in the brecciated rock shown in Fig. 1d by photometrically correcting the calibrated reflectance image (phase $0^{\circ}$, emission $0^{\circ}$, incidence $0^{\circ}$ ) using the photometric model developed in a companion paper [19]. We then calculate the mean albedos of 0.039 and 0.053 for the areas indicated in Extended Data Figure 2, representing the dark (blue outline) and bright (orange outline) clasts, respectively.

\section{Approach-phase observations}

The Approach phase of the mission began when the OCAMS PolyCam imager optically acquired Bennu from approximately 2 million km away on 17 August 2018. A schematic of the Approach timeline for the observations is given in Extended Data Figure 3. This phase provided opportunities to view and characterize Bennu as a point source. As the range between the OSIRIS-REx spacecraft and Bennu decreased, PolyCam and MapCam collected imagery with high enough spatial resolution to derive the shape model [16], constrain the spin state [20], measure the rotational lightcurves [20], derive the phase function [20], and measure the disk-integrated spectral properties [15]. In addition to observing and characterizing Bennu itself, the Approach observations were used to search the space immediately surrounding Bennu for dust and gas plumes and natural satellites within the Hill sphere [20]. Approach data were used to follow-up on ground-based observations of Bennu and to compare to the parameters in the mission's Design Reference Asteroid document [14]. 
Bennu phase function and color imaging-Disk-integrated phase function photometry observations consisted of different activities to ensure that the phase function of Bennu was properly determined at a number of phase angles. Full-rotation phase function observations took place on two separate dates when the phase angle was between $52^{\circ}$ and $55^{\circ}$ and again between $20^{\circ}$ and $50^{\circ}$.

These phase function observations were taken on a daily basis and used optical navigation (OpNav) targeting of Bennu. The observations began on 2 October 2018 and continued through 9 November 2018. After the daily OpNav observations were complete, MapCam was used to image Bennu with the following cadence of filters: single pan image - single b' image - single $\mathrm{v}$ image - single $\mathrm{w}$ image - single $\mathrm{x}$ image. The exposure times varied depending on the brightness of Bennu and were set to provide a signal-to-noise ratio of 100. Based on the expected brightness of Bennu throughout Approach, the exposure times needed to be changed once per week in order to ensure a signal-to-noise ratio of $\sim 100$ and prevent saturation of Bennu in the images. Individual images were obtained in succession as quickly as possible in order to minimize photometric variations due to the rotation of Bennu. The daily images covered a phase angle range from $62^{\circ}$ to nearly $0^{\circ}$.

The highest-resolution MapCam color mosaics shown in Figure 2 were produced using the data from the end of this observation set. MapCam imaged Bennu on 8 November 2018 at a phase angle $\sim 5^{\circ}$ and a pixel scale of $10.9 \mathrm{~m} /$ pixel.

Approach-phase PolyCam imaging-Between 9 and 25 November 2018, the observational plan was to point PolyCam nadir to Bennu and take 36 images, one at every $10^{\circ}$ of rotation (430 seconds). The observation parameters are given in Extended Data Table 1. In addition to the activities noted in the table, PolyCam images, taken every $10^{\circ}$ of rotation to support the spectroscopy observations [15], were also useful in developing the shape model of Bennu [16]. These observations give a long arc of data (out to 25 November 2018) over which to assess the pole direction and rotation rate [20].

Later in Approach, the field of view of PolyCam was small enough that we had to generate a mosaic of images to cover the area defined by the navigational uncertainties. The imaging conditions are given in Extended Data Table 2. The images were acquired with a 20\% image-overlap constraint and with a slew rate limit of $1.35 \mathrm{mrad} / \mathrm{s}$. This slew rate was set by using a 10-msec exposure time and allowing for 1-pixel blurring. The area to image was covered with a raster scan consisting of long slews with imaging and short non-imaging slews being used to traverse between lines. Most of the scans accommodate navigational uncertainties at the 3- $\sigma$ level or greater. The images acquired on the last two days of Approach (1 and 2 December 2018) were used to generate the global mosaic shown in Figure 3 as well as the features highlighted in Figures 1 and 3.

\section{Preliminary Survey}

The Preliminary Survey phase of the mission consisted of flybys over the north $(+Z)$ pole (three flybys), equator (one flyby), and south pole (one flyby). 
Preliminary Survey MapCam observations-MapCam observations of Bennu on the "distant" portions of the flybys were taken with a scan area sized to accommodate $2-\sigma$ navigational uncertainties. To satisfy the constraint of $10^{\circ}$ of rotational resolution, we increased the slew rate to $2.0 \mathrm{mrad} / \mathrm{s}$ from the $1.35 \mathrm{mrad} / \mathrm{s}$ value used for Approach. This higher slew rate limited the exposure time to $34 \mathrm{~ms}$ to avoid image blur greater than 1 pixel.

The observation parameters for all six MapCam data collection activities from the distant locations are presented in Extended Data Table 3. In addition to the size of the scans, which increase with decreasing range to the surface, the coordinates of nadir, expressed here in the Sun anti-momentum frame, also change from the beginning to the end of the activities.

Ten dark images were planned for each MapCam activity. Five dark images with the same exposure duration as the regular images were taken prior to the first raster scan slew, and an additional five dark images were taken following the completion of the last raster scan slew.

"Close" MapCam observations were taken on the outbound legs of the first and third north pole flybys and on the south pole flyby. The MapCam mosaics were planned around 2- $\sigma$ uncertainties and $20 \%$ image overlap. Ten dark images were also included, as for the "distant" observations. The observation parameters are given in Extended Data Table 4.

High-phase-angle MapCam data for photometric models-Sets of five MapCam images, one with pan and one with each of the four color filters, were taken at different times during Preliminary Survey. These observations span a range of phase angles from $\sim 38^{\circ}$ to $89^{\circ}$. These data contributed to achieving the accuracy and precision goals for the Global MapCam Photometric Model data products that were necessary to build the global imaging mosaics. These data products require six photometric models: one for each MapCam filter (panchromatic, b', v, w, \& x) and a PolyCam photometric model. Photometric models were used to photometrically correct global and local image mosaics. These photometrically corrected image mosaics were used as the base maps for viewing virtually all other acquired data. The MapCam color photometric models were used to photometrically correct the global and local MapCam color-ratio and true-color maps.

Shape model from stereophotoclinometry (SPC)—The shape model [16] was used to generate the elevation data shown in Figure 3. Details of the SPC processing are given in a companion paper [16]. The shape modelling activities used data from PolyCam imaging during Approach and MapCam imaging during Preliminary Survey. From the shape model, we derive spin-state parameters and identified a prime meridian and coordinate system (used in Figure 3). Upon encountering Bennu, a geologic feature was identified and henceforth used as the location of Bennu's prime meridian. As higher-resolution imagery is obtained throughout the mission and the selected geologic feature location becomes clearer, the precise location of the prime meridian will be updated.

\section{Data Availability}

Data underlying the plots in Figs. 1 and 2 are available with this manuscript as Source Data. Raw through calibrated datasets will be available via the Small Bodies Node of the Planetary Data System (PDS) (https://pds-smallbodies.astro.umd.edu/). Data are delivered to the PDS 
according to the OSIRIS-REx Data Management Plan available in the OSIRIS-REx PDS archive. Higher-level products, e.g., global mosaics, elevation maps, will be available in the Planetary Data System PDS 1 year after departure from the asteroid.

\section{Code Availability}

The ISIS3 code used to generate the image processing data products is available from the U.S. Geological Survey-Astrogeology Branch.

\section{Extended Data}




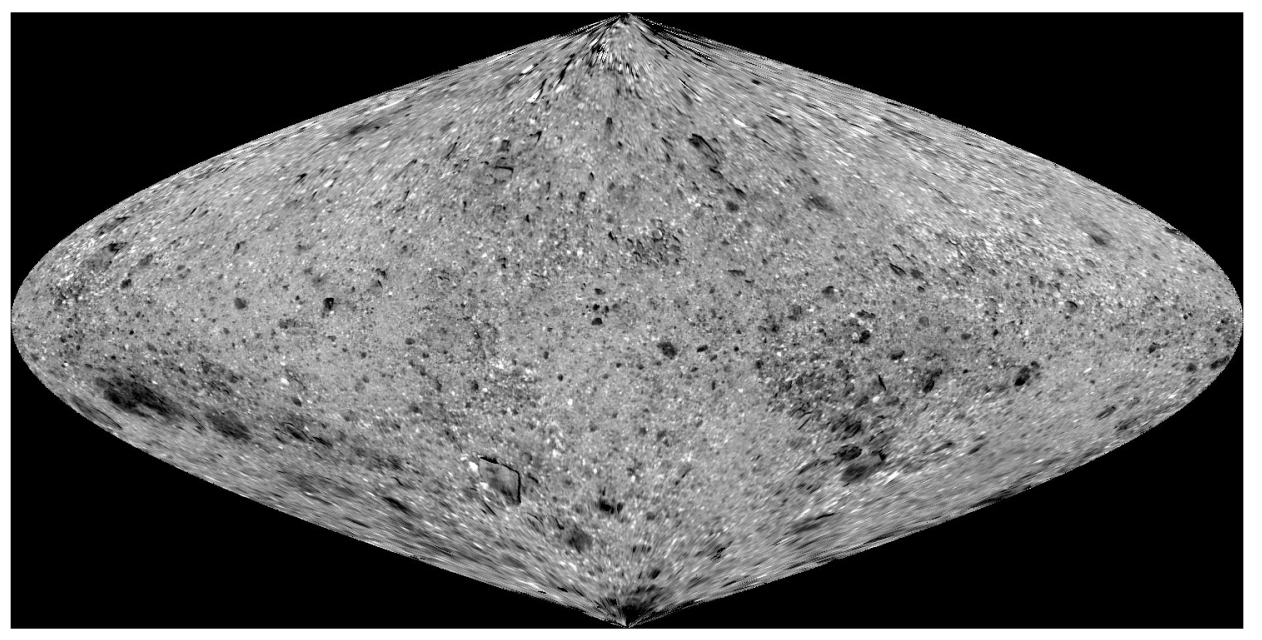

Extended Data Figure 1.

The global mosaic of Bennu projected onto a sinusoidal map that preserves area. The PolyCam images were photometrically corrected to mimic imaging conditions with phase, emission, and incidence angles of $0^{\circ}$. The map has a pixel scale of $1.2 \mathrm{~m} /$ pixel. Images were taken on 25 November 2018. 


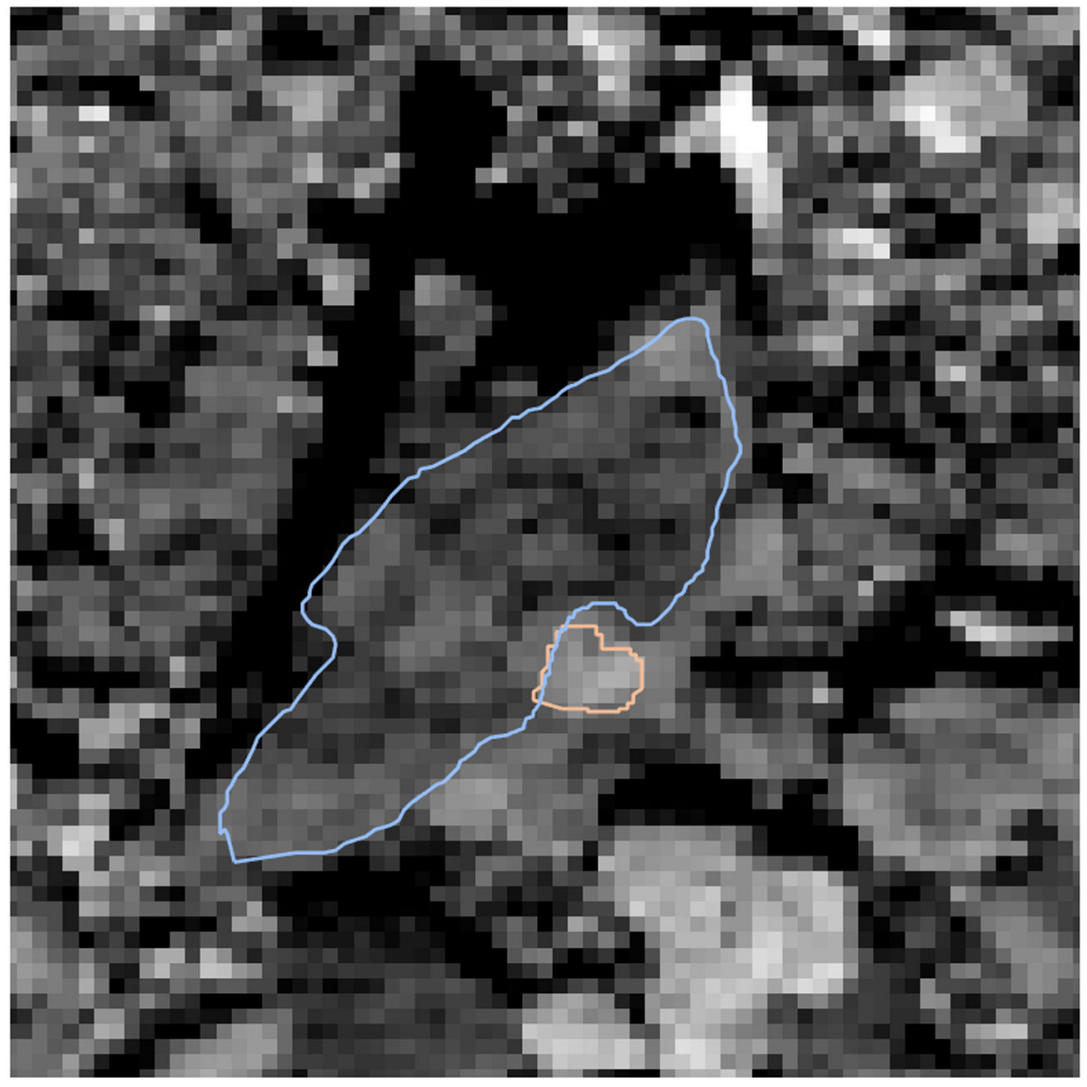

Extended Data Figure 2.

Areas for calculation of albedo variation in Fig. 1d. 


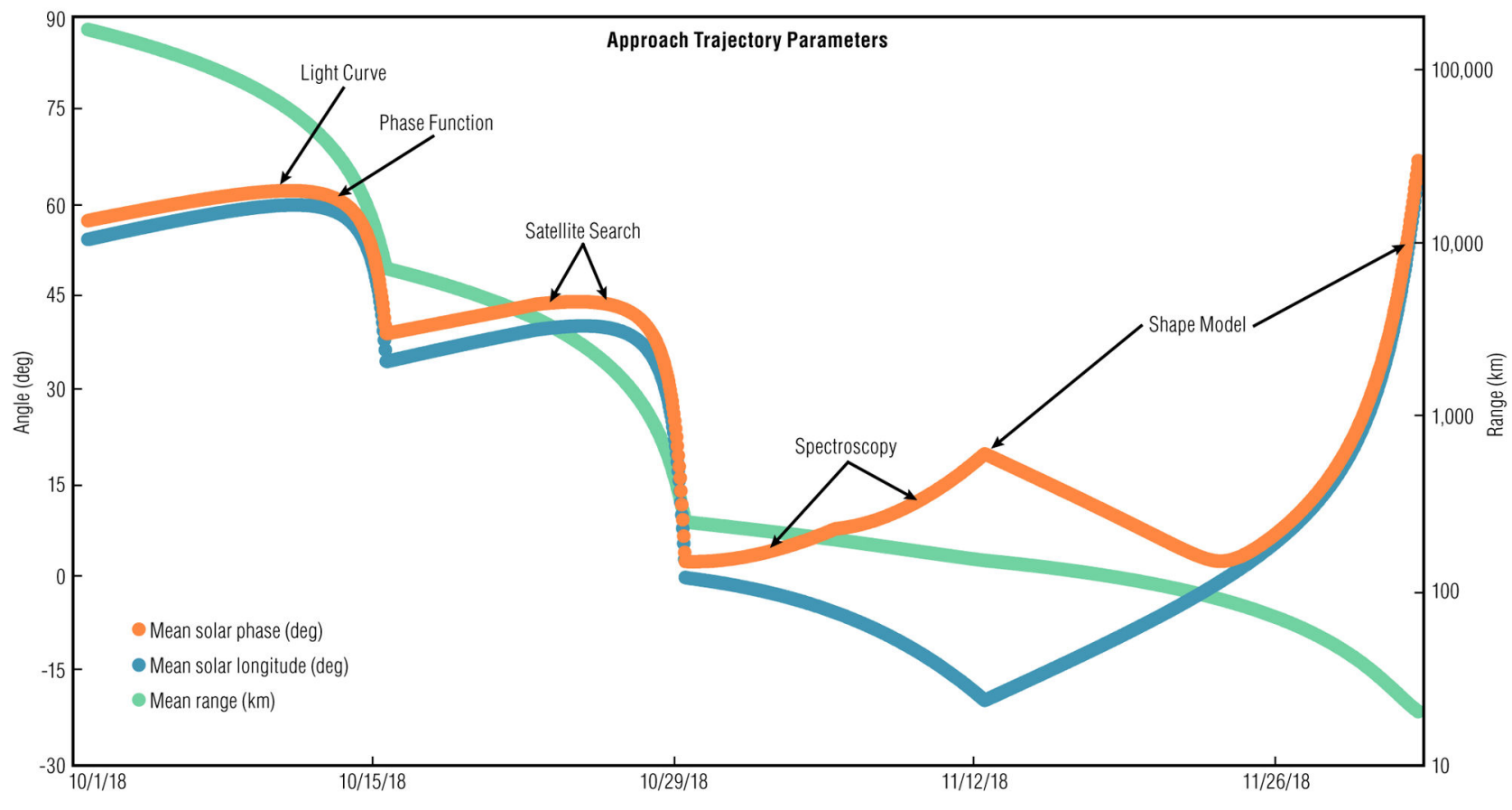

Extended Data Figure 3.

Timeline of the various observations made during the Approach Phase. 


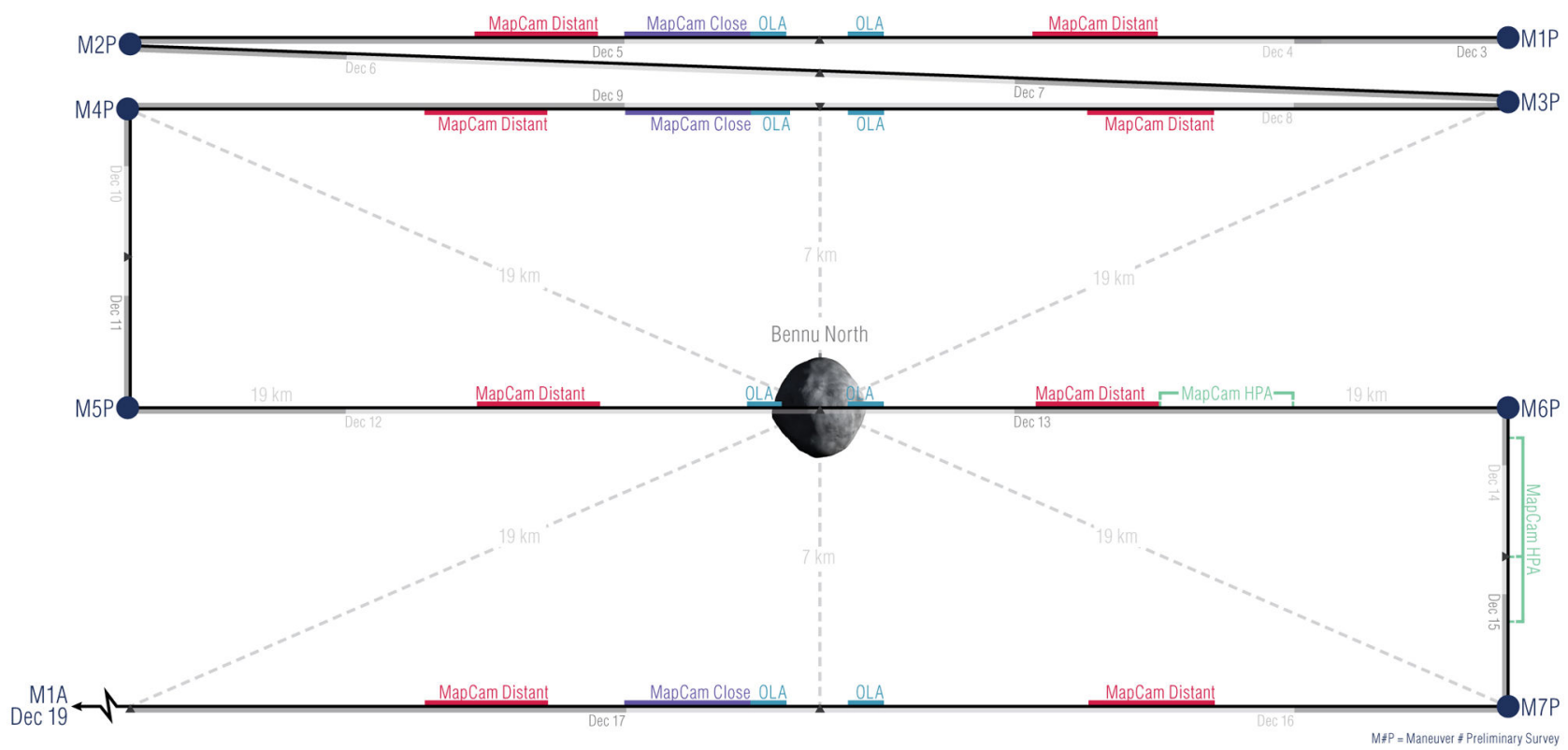

Extended Data Figure 4. Schematic of Preliminary Survey showing three passes over the North Pole.

Each trajectory leg lasts two days. The observations consist of MapCam mosaics made far from Bennu, both on the inbound and outbound legs from closest approach, OLA observations made near closest approach, both inbound and outbound, and additional MapCam mosaics made soon after the OLA observations but on the outbound legs of the polar flybys only. The times of closest approach to the pole was set at a nominal 17:00 UTC for all flybys.

Extended Data Table 1.

Observation parameters for early PolyCam images.

\begin{tabular}{|c|c|c|c|c|c|c|}
\hline Parameter & $11 / 12 / 18$ & $11 / 13 / 18$ & $11 / 16 / 18$ & $11 / 19 / 18$ & $11 / 23 / 18$ & $11 / 25 / 18$ \\
\hline Solar Longitude (deg) & -19.1 & -18.8 & -13.8 & -8.7 & -1.1 & 3.4 \\
\hline Sigma Solar Longitude (deg) & 0.4 & 0.3 & 0.3 & 0.4 & 0.7 & 1.0 \\
\hline Equivalent local time & $10: 43$ & $10: 44$ & $11: 04$ & $11: 25$ & $11: 55$ & $12: 13$ \\
\hline Solar Latitude (deg) & 0.0 & 0.1 & 0.6 & 1.2 & 2.4 & 3.3 \\
\hline Sigma Solar Latitude (deg) & 0.4 & 0.3 & 0.4 & 0.5 & 0.8 & 1.1 \\
\hline Phase angle (deg) & 19.1 & 18.8 & 13.8 & 8.8 & 2.6 & 4.7 \\
\hline Range (km) & 151.8 & 147.4 & 134.9 & 119.7 & 95.0 & 80.6 \\
\hline PolyCam FOV (m) & 2094 & 2034 & 1862 & 1652 & 1311 & 1113 \\
\hline PolyCam pixel size (m) & 2.0 & 2.0 & 1.8 & 1.6 & 1.3 & 1.1 \\
\hline Total number of images & 36 & 36 & 36 & 36 & 36 & 36 \\
\hline
\end{tabular}


Extended Data Table 2.

Observation parameters for late PolyCam images.

\begin{tabular}{|c|c|c|c|c|}
\hline Parameter & $11 / 27 / 18$ & $11 / 29 / 18$ & 12/1/18 & $12 / 2 / 18$ \\
\hline Solar Longitude (deg) & 9.0 & 17.1 & 33.0 & 48.9 \\
\hline Sigma Solar Longitude (deg) & 1.4 & 2.3 & 3.7 & 3.4 \\
\hline Equivalent local time & $12: 36$ & 13:08 & $14: 12$ & $15: 15$ \\
\hline Sigma local time & $0: 05$ & 0:09 & $0: 14$ & $0: 13$ \\
\hline Solar Latitude (deg) & 4.7 & 7.2 & 12.4 & 16.8 \\
\hline Sigma Solar Latitude (deg) & 1.6 & 2.4 & 3.2 & 2.4 \\
\hline Phase angle (deg) & 10.2 & 18.6 & 35.3 & 51.7 \\
\hline Range (km) & 65.0 & 48.4 & 31.2 & 23.8 \\
\hline PolyCam FOV (m) & 897 & 668 & 430 & 328 \\
\hline PolyCam pixel size (m) & 0.9 & 0.7 & 0.4 & 0.3 \\
\hline Number of scan lines & 2 & 4 & 4 & 5 \\
\hline Number of images per line & 2 & 4 & 4 & 6 \\
\hline Total number of images per mosaic & 4 & 16 & 16 & 30 \\
\hline Number of mosaics & 36 & 28 & 36 & 26 \\
\hline Total number of images & 144 & 448 & 576 & 780 \\
\hline
\end{tabular}

\section{Extended Data Table 3.}

Observation parameters for Preliminary Survey distant MapCam activities.

\begin{tabular}{|c|c|c|c|c|c|c|c|c|c|c|c|c|c|c|c|}
\hline \multirow[t]{2}{*}{ Parameter } & \multicolumn{4}{|c|}{ North Pole-1 } & \multicolumn{4}{|c|}{ North Pole-3 } & \multicolumn{4}{|c|}{ Equator } & \multicolumn{3}{|c|}{ South Pr } \\
\hline & $\begin{array}{r}\text { Inbo } \\
(12\end{array}$ & & $\begin{array}{r}\text { Outh } \\
\text { (1) }\end{array}$ & bund & $\begin{array}{r}\text { Inbc } \\
(12\end{array}$ & $\begin{array}{l}\text { ind } \\
\text { 8) }\end{array}$ & $\begin{array}{r}\text { Out } \\
(1\end{array}$ & $\begin{array}{l}\text { und } \\
\text { 9) }\end{array}$ & $\begin{array}{r}\text { Inbc } \\
(12\end{array}$ & $\begin{array}{l}\text { und } \\
\text { 12) }\end{array}$ & $\begin{array}{r}\text { Outl } \\
(12\end{array}$ & $\begin{array}{l}\text { ound } \\
13 \text { ) }\end{array}$ & $\begin{array}{r}\text { Inb } \\
(12\end{array}$ & $\begin{array}{l}\text { Ind } \\
\text { 6) }\end{array}$ & \\
\hline & Start & End & Start & End & Start & End & Start & End & Start & End & Start & End & Start & End & $S$ \\
\hline Observation Time (UTC) & $4: 45$ & $9: 15$ & $0: 45$ & $5: 15$ & $2: 52$ & $7: 22$ & $2: 45$ & $7: 15$ & $4: 45$ & $9: 15$ & $0: 45$ & $5: 15$ & $2: 52$ & $7: 22$ & 2 \\
\hline $\begin{array}{l}\text { Distance to Bennu center } \\
(\mathrm{km})\end{array}$ & 11.4 & 9.1 & 9.1 & 11.4 & 12.4 & 10.0 & 10.0 & 12.5 & 11.1 & 8.8 & 8.8 & 11.1 & 12.5 & 10.0 & \\
\hline $\begin{array}{l}\text { Latitude of nadir (deg- } \\
\text { SAM) }\end{array}$ & 39.2 & 52.3 & 52.4 & 39.3 & 35.2 & 46.1 & 45.9 & 35.1 & 0.0 & 0.0 & 0.0 & 0.0 & -35.1 & -46.0 & \\
\hline $\begin{array}{l}\text { Longitude of nadir (deg- } \\
\text { SAM) }\end{array}$ & 89.8 & 89.9 & -89.9 & -89.8 & 94.4 & 94.5 & -85.2 & -85.1 & -51.6 & -38.2 & 37.9 & 51.4 & 89.7 & 89.8 & \\
\hline Radial 1- $\sigma$ uncertainty (m) & 299 & 300 & 210 & 290 & 238 & 244 & 280 & 285 & 139 & 138 & 136 & 135 & 165 & 169 & \\
\hline $\begin{array}{l}\text { Transverse } 1-\sigma \\
\text { uncertainty }(\mathrm{m})\end{array}$ & 231 & 244 & 495 & 528 & 307 & 263 & 237 & 280 & 143 & 127 & 146 & 170 & 171 & 163 & \\
\hline $\begin{array}{l}\text { Normal } 1-\sigma \text { uncertainty } \\
(\mathrm{m})\end{array}$ & 369 & 332 & 241 & 235 & 253 & 235 & 239 & 257 & 187 & 174 & 159 & 165 & 230 & 230 & \\
\hline Phase Angle to nadir (deg) & 89.8 & 89.9 & 89.9 & 89.8 & 94.4 & 94.5 & 85.2 & 85.1 & 51.6 & 38.2 & 37.9 & 51.4 & 89.7 & 89.8 & \\
\hline MapCam FOV (m) & 766 & 612 & 612 & 766 & 841 & 673 & 675 & 842 & 746 & 590 & 589 & 746 & 842 & 675 & \\
\hline MapCam pixel size $(\mathrm{cm})$ & 74.8 & 59.8 & 59.7 & 74.8 & 82.1 & 65.7 & 65.9 & 82.2 & 72.9 & 57.6 & 57.5 & 72.8 & 82.2 & 65.9 & \\
\hline
\end{tabular}

Nature. Author manuscript; available in PMC 2019 October 01. 


\begin{tabular}{|c|c|c|c|c|c|c|c|c|c|c|c|c|c|}
\hline \multirow[t]{2}{*}{ Parameter } & \multicolumn{3}{|c|}{ North Pole-1 } & \multicolumn{4}{|c|}{ North Pole-3 } & \multicolumn{4}{|c|}{ Equator } & \multicolumn{2}{|c|}{ South } \\
\hline & $\begin{array}{l}\text { Inbound } \\
(12 / 4)\end{array}$ & & $\begin{array}{l}\text { ound } \\
2 / 5)\end{array}$ & $\begin{array}{r}\text { Inb } \\
(1\end{array}$ & $\begin{array}{l}\text { und } \\
\text { (8) }\end{array}$ & & $\begin{array}{l}\text { ound } \\
\text { (9) }\end{array}$ & & $\begin{array}{l}\text { ound } \\
/ 12)\end{array}$ & $\begin{array}{r}\text { Out } \\
(1\end{array}$ & $\begin{array}{l}\text { ound } \\
\text { 13) }\end{array}$ & & $\begin{array}{l}\text { ound } \\
2 / 16)\end{array}$ \\
\hline Mosic Size & $2 \times 3 \quad 3 \times 3$ & $5 \times 3$ & $5 \times 2$ & $3 \times 2$ & $3 \times 2$ & $3 \times 3$ & $3 \times 2$ & $2 \times 2$ & $2 \times 2$ & $2 \times 2$ & $2 \times 2$ & $2 \times 2$ & $2 \times 2$ \\
\hline Rotational resolution (deg) & 12 & \multicolumn{2}{|c|}{15} & \multicolumn{2}{|c|}{10} & \multicolumn{2}{|c|}{10} & \multicolumn{2}{|c|}{10} & \multicolumn{2}{|c|}{10} & \multicolumn{2}{|r|}{10} \\
\hline $\begin{array}{l}\text { Number of images per } \\
\text { activity }\end{array}$ & 267 & \multicolumn{2}{|c|}{270} & \multicolumn{2}{|c|}{216} & \multicolumn{2}{|c|}{219} & \multicolumn{2}{|c|}{144} & \multicolumn{2}{|c|}{144} & \multicolumn{2}{|r|}{144} \\
\hline
\end{tabular}

\section{Extended Data Table 4.}

Observation parameters for close MapCam activities.

\begin{tabular}{|c|c|c|c|c|c|c|}
\hline \multirow[t]{2}{*}{ Parameter } & \multicolumn{2}{|c|}{ North Pole } & \multicolumn{2}{|c|}{ North Pole } & \multicolumn{2}{|c|}{ South Pole } \\
\hline & \multicolumn{2}{|c|}{$12 / 4 / 18$} & \multicolumn{2}{|c|}{$12 / 8 / 18$} & \multicolumn{2}{|c|}{$12 / 16 / 18$} \\
\hline & Start & End & Start & End & Start & End \\
\hline Observation Time (UTC) & $19: 30$ & 24:00 & $19: 30$ & $24: 00$ & $19: 30$ & 24:00 \\
\hline Distance to center of Bennu (km) & 7.48 & 8.81 & 7.47 & 8.80 & 7.54 & 8.88 \\
\hline Latitude of nadir (deg-SAM) & 76.1 & 55.2 & 76.3 & 55.3 & -76.4 & -55.4 \\
\hline Radial $1-\sigma$ uncertainty (m) & 201 & 200 & 284 & 281 & 186 & 184 \\
\hline Transverse $1-\sigma$ uncertainty $(m)$ & 425 & 488 & 179 & 211 & 153 & 167 \\
\hline Normal $1-\sigma$ uncertainty $(m)$ & 262 & 243 & 222 & 230 & 234 & 236 \\
\hline Phase Angle to nadir (deg) & 90.0 & 89.9 & 85.3 & 85.2 & 90.0 & 89.9 \\
\hline MapCam FOV (m) & 516 & 608 & 516 & 607 & 521 & 613 \\
\hline MapCam pixel size $(\mathrm{cm})$ & 50 & 59 & 50 & 59 & 51 & 60 \\
\hline Mosaic size & $5 \times 3$ & $6 \times 3$ & $3 \times 3$ & $3 \times 3$ & $3 \times 3$ & $3 \times 3$ \\
\hline Rotational resolution (deg) & \multicolumn{2}{|c|}{18} & \multicolumn{2}{|c|}{12} & \multicolumn{2}{|c|}{12} \\
\hline Number of images per activity & \multicolumn{2}{|c|}{327} & \multicolumn{2}{|c|}{270} & \multicolumn{2}{|c|}{270} \\
\hline
\end{tabular}

\section{Acknowledgements}

This material is based upon work supported by NASA under Contract NNM10AA11C issued through the New Frontiers Program.

\section{References}

1. Lauretta DS et al. The OSIRIS-REx target asteroid (101955) Bennu: Constraints on its physical, geological, and dynamical nature from astronomical observations. Meteoritics Planet. Sci 50, 834849 (2015).

2. Hergenrother CW et al. Lightcurve, color and phase function photometry of the OSIRIS-REx target asteroid (101955) Bennu. Icarus 226, 663-670 (2013).

3. Clark BE et al. Asteroid (101955) 1999 RQ36: Spectroscopy from 0.4 to $2.4 \mu \mathrm{m}$ and meteorite analogs. Icarus 216, 462-475 (2011).

4. Lauretta DS et al. OSIRIS-REx: Sample return from asteroid (101955) Bennu. Space Sci. Rev 212, 925-984 (2017). 
5. Emery JP, Fernández YR, Kelley MSP, Warden KT, Hergenrother C, Lauretta DS, Drake MJ, Campins H, and Ziffer J. "Thermal infrared observations and thermophysical characterization of OSIRIS-REx target asteroid (101955) Bennu.” Icarus 234, 17-35 (2014).

6. Nolan MC et al. Shape model and surface properties of the OSIRIS-REx target Asteroid (101955) Bennu from radar and lightcurve observations. Icarus 226, 629-640 (2013).

7. Daly MG et al. The OSIRIS-REx Laser Altimeter (OLA) investigation and instrument. Space Sci. Rev 214, 212, 899-924 (2017).

8. Bierhaus EB et al. The OSIRIS-REx spacecraft and the Touch-and-Go Sample Acquisition Mechanism (TAGSAM). Space Sci. Rev 214, 107 (2018).

9. Christensen PR et al. The OSIRIS-REx thermal emission spectrometer (OTES) instrument. Space Sci. Rev 214, 87 (2018).

10. Reuter DC et al. The OSIRIS-REx visible and infrared spectrometer (OVIRS): Spectral maps of the asteroid Bennu. Space Sci. Rev 214, 54 (2018).

11. Rizk B et al. OCAMS: the OSIRIS-REx camera suite. Space Sci. Rev 214, 26 (2018).

12. Masterson RA et al. Regolith X-Ray Imaging Spectrometer (REXIS) Aboard the OSIRIS-REx Asteroid Sample Return Mission. Space Sci. Rev 214, 48 (2018).

13. McMahon JW, Scheeres DJ, Hesar SG, Farnocchia D, Chesley S, and Lauretta D. "The OSIRISREx radio science experiment at Bennu." Space Sci. Rev 214, 43 (2018).

14. Hergenrother $\mathrm{CW}$ et al. The design reference asteroid for the OSIRIS-REx Mission Target (101955) Bennu. Preprint at https://arxiv.org/abs/1409.4704 (2014).

15. Hamilton VE et al. Evidence for widespread hydrated minerals on asteroid (101955) Bennu. Nat. Astron, in press.

16. Barnouin OS et al. Shape of (101955) Bennu indicative of a rubble pile with internal stiffness. Nat. Geosci, in press.

17. Scheeres DJ et al. The dynamic geophysical environment of (101955) Bennu based on OSIRISREx measurements. Nat. Astron, in press.

18. Walsh KJ et al. Craters, boulders and regolith of (101955) Bennu indicative of an old and dynamic surface. Nat. Geosci, in press.

19. DellaGiustina DN, Emery JP et al. Boulders with a chance of dust on asteroid (101955) Bennu. Nat. Astron, in press.

20. Hergenrother CW et al. Operational environment and rotational acceleration of asteroid (101955) Bennu from OSIRIS-REx observations. Nat. Commun, in press.

21. Campins $\mathrm{H}$ et al. Compositional diversity among primitive asteroids In Primitive Meteorites and Asteroids (ed. Abreu N), pp. 345-369 (Elsevier, 2018).

22. Izawa MRM et al. Spectral reflectance properties of magnetites: Implications for remote sensing. Icarus 319, 525-539 (2019).

23. Kerridge JF, Mackay AL, Boynton WV Magnetite in CI carbonaceous meteorites: Origin by aqueous activity on a planetesimal surface. Science 205, 395-397 (1979). [PubMed: 17790849]

24. Rubin AE, Trigo-Rodríguez JM, Huber H, Wasson JT Progressive aqueous alteration of CM carbonaceous chondrites. Geochim. Cosmochim. Acta 71, 2361-2382 (2007).

25. Brearley AJ The action of water In Meteorites and the Early Solar System II (ed. Lauretta DS, McSween HY Jr.), pp. 587-624 (University of Arizona Press, Tucson, AZ, 2006).

26. Lantz C, Binzel RP, DeMeo FE Space weathering trends on carbonaceous asteroids: A possible explanation for Bennu's blue slope? Icarus 302, 10-17 (2018).

27. Thompson MS, Loeffler MJ, Morris RV, Keller LP, \& Christoffersen R Spectral and chemical effects of simulated space weathering of the Murchison CM2 carbonaceous chondrite. Icarus 319, 499-511 (2019).

28. Bischoff A, Scott ER, Metzler K, \& Goodrich CA Nature and origins of meteoritic breccias In Meteorites and the Early Solar System II (ed. Lauretta DS, McSween HY Jr.), pp. 679-712 (University of Arizona Press, Tucson, AZ, 2006).

29. Delbo $M$ et al. Thermal fatigue as the origin of regolith on small asteroids. Nature 508, 233-236 (2014). [PubMed: 24695219] 
30. Gundlach B \& Blum J A new method to determine the grain size of planetary regolith. Icarus 223, 479-492 (2013).

31. Scheeres DJ et al. The geophysical environment of Bennu. Icarus 276 116-140 (2016).

32. Binzel RP et al. Spectral slope variations for OSIRIS-REx target Asteroid (101955) Bennu: Possible evidence for a fine-grained regolith equatorial ridge. Icarus 256, $22-29$ (2015).

33. OSIRIS-REx, Mission Status Update, 2 11, 2019, https://www.asteroidmission.org/? mission_update=feb-11-2019 (2019).

34. DellaGiustina DN et al. Overcoming the Challenges Associated with Image-Based Mapping of Small Bodies in Preparation for the OSIRIS-REx Mission to (101955) Bennu. Earth Space Sci 5, 929-949 (2018). 


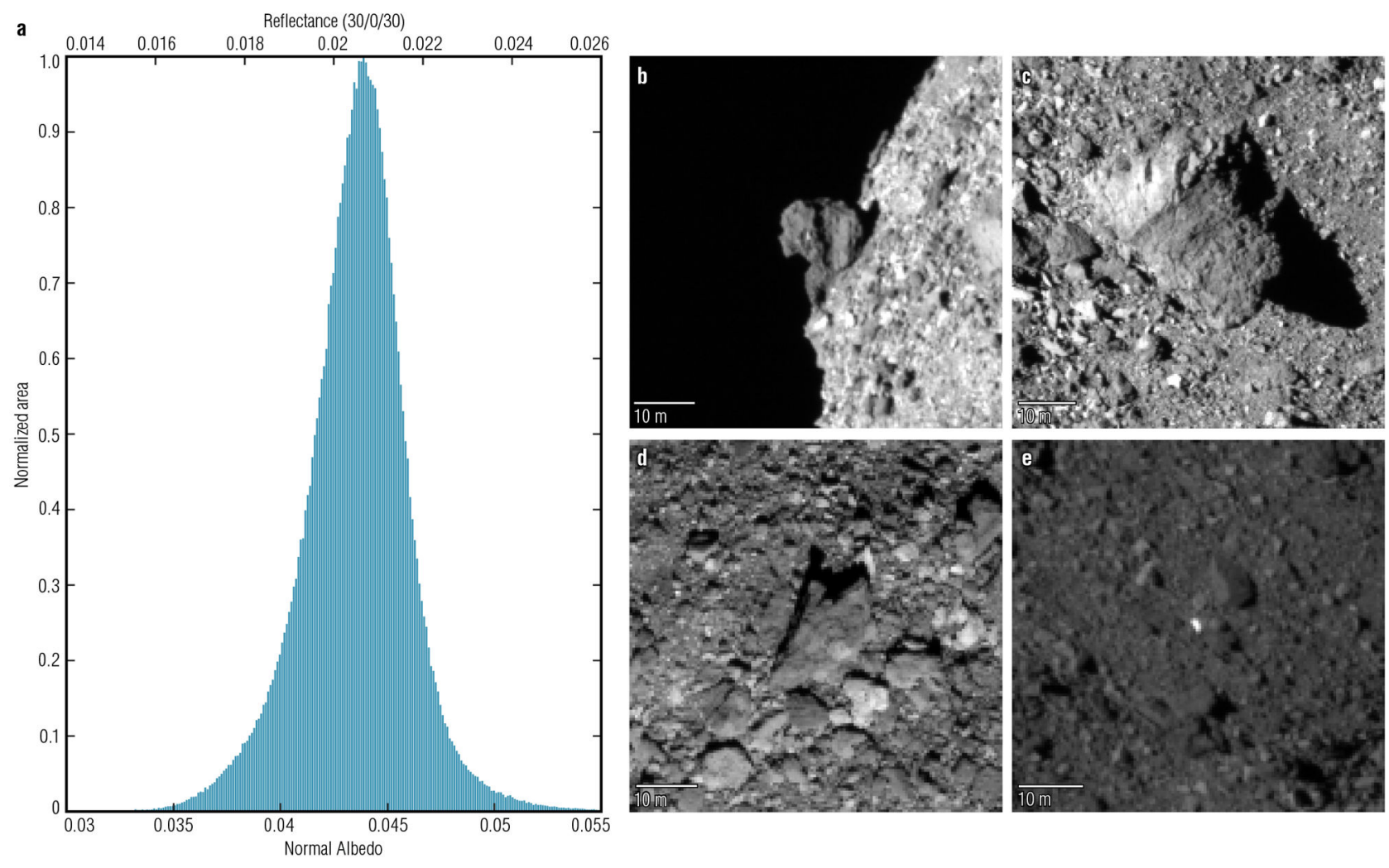

Figure 1. Range of albedo on the surface of Bennu.

a, Histogram describing the normal albedo distribution of Bennu's surface based on lowphase-angle images acquired by the PolyCam imager [9] on 25 November 2018. The axis along the top of the plot gives values for the same data when corrected to standard laboratory conditions $\left(30^{\circ}\right.$ phase, $0^{\circ}$ emission, $30^{\circ}$ incidence) to enable direct comparison to the meteorite record. $\mathbf{b}$ to e, PolyCam images acquired on 1 and 2 December 2018 highlight the range of albedo heterogeneity on Bennu. b. One of the darkest boulders $(\sim 3.3 \%$ normal albedo), perched on the surface of the asteroid (phase angle $51^{\circ}, 0.32 \mathrm{~m} / \mathrm{pixel}$ ). c, A $30-\mathrm{m}$ boulder that defines the prime meridian and has a near-average albedo of $\sim 4 \%$ (phase angle $49^{\circ}, 0.32 \mathrm{~m} / \mathrm{pixel}$ ). d, A boulder includes a clast that is $33 \%$ brighter than its host matrix (phase angle $33^{\circ}, 0.43 \mathrm{~m} /$ pixel; see methods). e, The brightest object identified thus far on Bennu (phase angle $34^{\circ}, 0.42 \mathrm{~m} /$ pixel). 

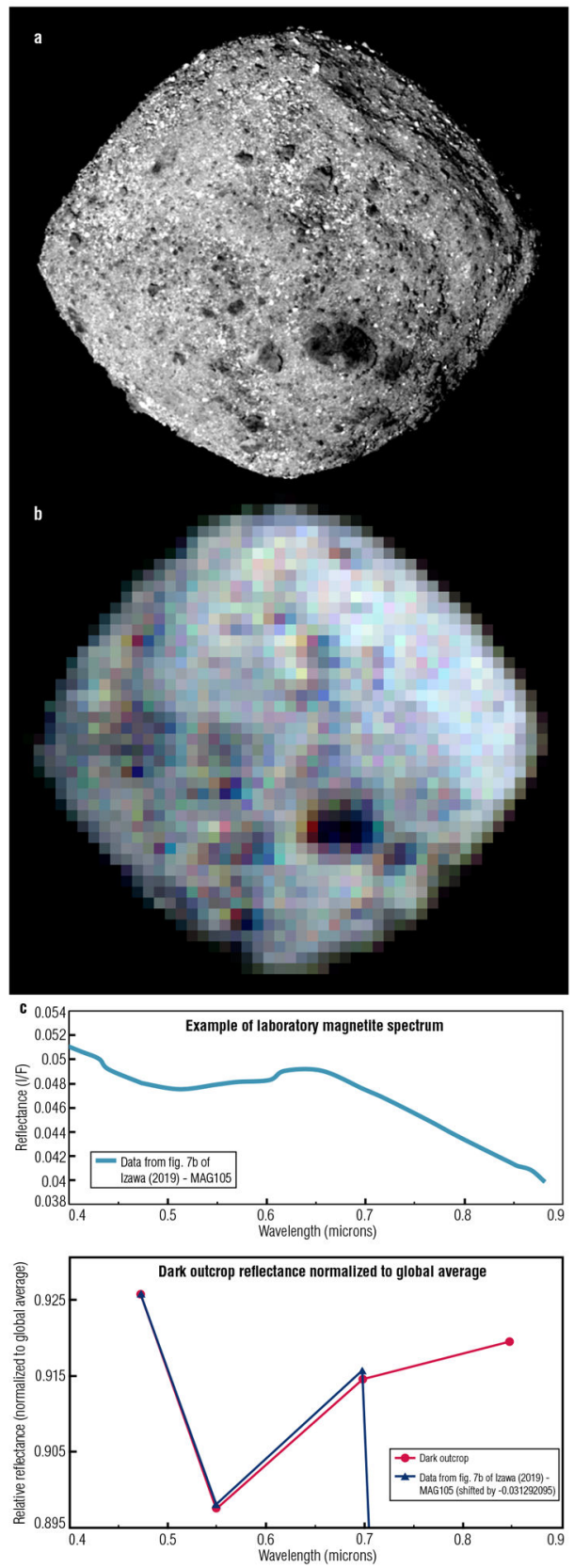

Figure 2. OCAMS imaging data elucidate Bennu's diverse surface reflectance and composition. a, Image acquired by the PolyCam imager on 25 November 2018 at a phase angle of $\sim 5^{\circ}$ and a pixel scale of $\sim 1.1 \mathrm{~m} /$ pixel. $\mathbf{b}$, Color mosaic acquired by the MapCam imager [9] on 8 November 2018 at a phase angle of $\sim 5^{\circ}$ and a pixel scale of $10.9 \mathrm{~m} /$ pixel (coarse pixel scale is due to the wider field of view of the MapCam). c, The upper plot shows a full laboratory spectrum of magnetite [22]. The lower plot shows the laboratory magnetite spectrum in a manner comparable to the broadband spectrum from the 8 November MapCam data for the large dark outcrop on Bennu's surface (evident in the lower center-right of panels a and b). Both spectra in the lower plot are normalized to the global average reflectance of Bennu. In 
combination with OTES data [15], the 0.55- $\mu \mathrm{m}$ absorption feature in the MapCam data indicates the presence of magnetite on Bennu. 

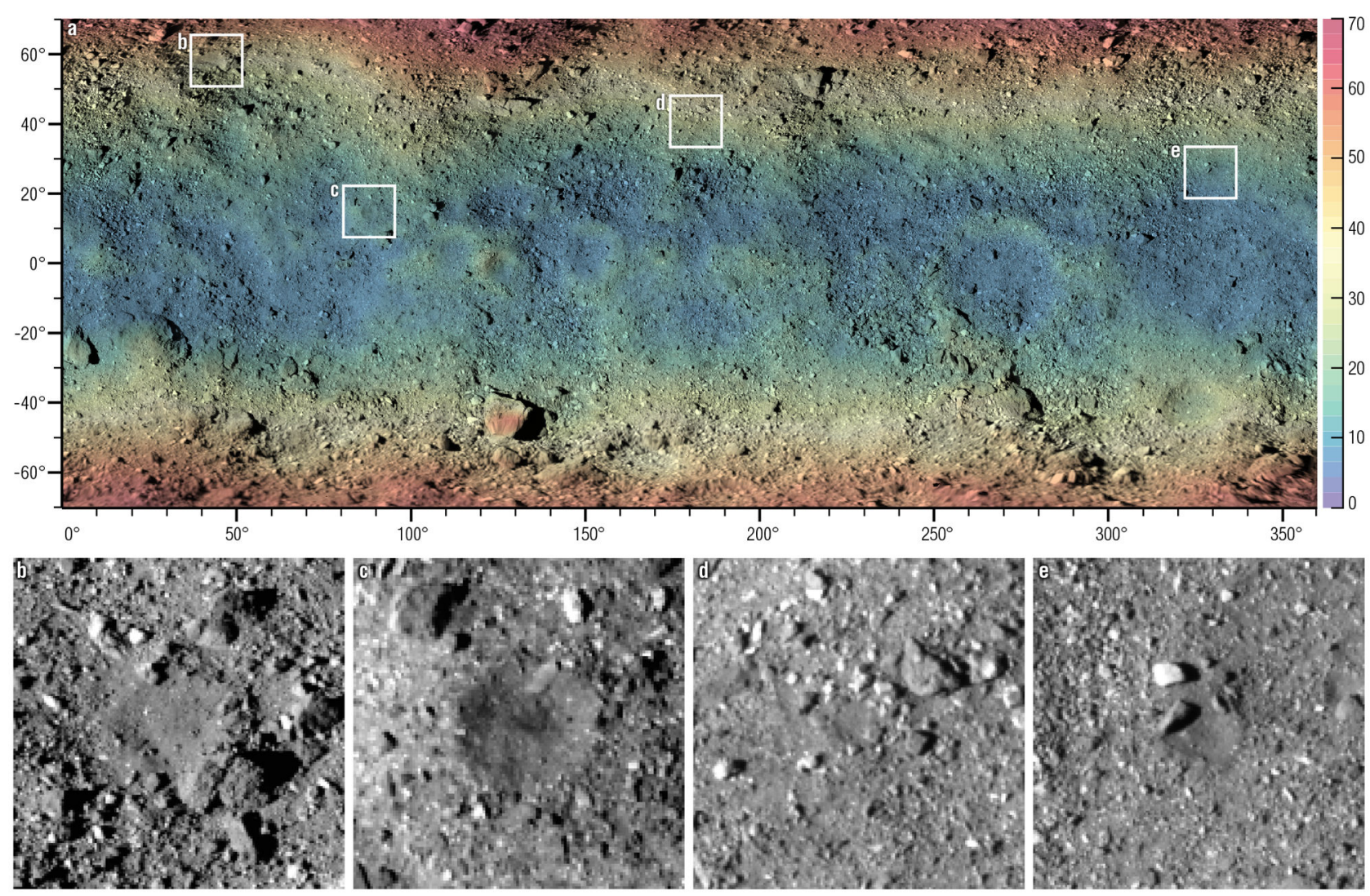

Figure 3. OCAMS global mosaic overlain with elevation data and four regions of interest for sampling.

a, The surface of Bennu is covered by numerous boulders at the meter scale or larger. The color scale of the overlay shows elevation above the geopotential from $0 \mathrm{~m}$ (blue) to $70 \mathrm{~m}$ (red). Tick marks indicate latitude and longitude. The global mosaic consists of PolyCam images taken on 1 December 2018 and MapCam images taken on 13 December 2018. White boxes corresponding to the images in panels $\mathbf{b}$ to $\mathbf{e}$ highlight regions of interest for sampling that appear fine-grained and relatively free of spacecraft hazards. Each of the boxes is $50 \mathrm{~m}$ wide, the sampling-design requirement for OSIRIS-REx navigational guidance accuracy. $\mathbf{b}$, OCAMS image acquired on 1 December 2018 at a phase angle of $34.75^{\circ}$ and a pixel scale of $0.42 \mathrm{~m} /$ pixel. c, OCAMS image acquired on 2 December 2018 at a phase angle of $49.25^{\circ}$ and a pixel scale of $0.33 \mathrm{~m} /$ pixel. d, OCAMS image acquired on 2 December 2018 at a phase angle of $50.65^{\circ}$ and a pixel scale of $0.32 \mathrm{~m} /$ pixel. e, OCAMS image acquired on 2 December 2018 at a phase angle of $48.40^{\circ}$ and a pixel scale of $0.33 \mathrm{~m} /$ pixel. 
Table 1.

The Design Reference Asteroid scorecard, a comparison of the properties of Bennu determined from pre-encounter versus OSIRIS-REx data.

Pre-encounter astronomical observations accurately characterized many of the asteroid's characteristics [1]. Most values are well within 1-sigma of the spacecraft-based measurements. The main area where the preencounter data are inaccurate is the compositional diversity and roughness of the surface, creating a challenge for safe collection of a representative sample.

\begin{tabular}{|c|c|c|}
\hline Property & $\begin{array}{l}\text { Pre-Encounter } \\
\text { Value }( \pm 1 \sigma)\end{array}$ & $\begin{array}{l}\text { OSIRIS-REx } \\
\text { Value }( \pm 1 \sigma)\end{array}$ \\
\hline \multicolumn{3}{|c|}{ Size and Shape } \\
\hline Mean Diameter (m) & $492 \pm 20$ & $490.06 \pm 0.16$ \\
\hline Polar Extent (m) & $508 \pm 52$ & $498.49 \pm 0.12$ \\
\hline Equatorial Extent (m) & $565 \pm 10 \times 535 \pm 10$ & $564.73 \pm 0.12 \times 536.10 \pm 0.12$ \\
\hline Volume $\left(\mathrm{km}^{3}\right)$ & $0.062 \pm 0.006$ & $0.0615 \pm 0.0001$ \\
\hline Surface Area $\left(\mathrm{km}^{2}\right)$ & $0.79 \pm 0.04$ & $0.782 \pm 0.004$ \\
\hline \multicolumn{3}{|c|}{ Mass and Density } \\
\hline Bulk Density $\left(\mathrm{kg} \mathrm{m}^{-3}\right)$ & $1260 \pm 70$ & $1190 \pm 13$ \\
\hline Mass $\left(10^{10} \mathrm{~kg}\right)$ & $7.8 \pm 0.9$ & $7.329 \pm 0.009$ \\
\hline $\mathrm{GM}\left(\mathrm{m}^{3} \mathrm{~s}^{-2}\right)$ & $5.2 \pm 0.6$ & $4.892 \pm 0.006$ \\
\hline Hill Sphere Radius (km) & $31.7+3.3 /-4.2$ & $31.05 \pm 0.01$ \\
\hline \multicolumn{3}{|c|}{ Rotational Properties } \\
\hline Sidereal Rotation Period (h) & $4.297 \pm 0.002$ & $4.296056 \pm 0.000002$ \\
\hline Obliquity $\left({ }^{\circ}\right)$ & $178 \pm 4$ & $177.6 \pm 0.11$ \\
\hline Pole Position (RA, DEC, J2000) $\left(^{\circ}\right)$ & $+87 \pm 3,-65 \pm 3$ & $+85.65 \pm 0.12,-60.17 \pm 0.09$ \\
\hline Rotational Acceleration $\left(10^{-6}\right.$ deg day $\left.^{-2}\right)$ & $2.64 \pm 1.05$ & $3.63 \pm 0.52$ \\
\hline $\mathrm{COM} / \mathrm{COF}^{*}$ Offset $[\mathrm{x}, \mathrm{y}, \mathrm{z}](\mathrm{m})$ & Undetermined & {$[1.38 \pm 0.04,-0.43 \pm 0.07,-0.12 \pm 0.27]$} \\
\hline Products of Inertia ${ }^{* *}\left(\mathrm{~m}^{2}\right)$ & Undetermined & $\begin{array}{c}I_{z x}=-46.70 \pm 0.05 \\
I_{z y}=11.39 \pm 0.01\end{array}$ \\
\hline Non-principal Axis Rotation $\left({ }^{\circ}\right)$ & No evidence & $<0.2 \pm 0.2$ \\
\hline \multicolumn{3}{|c|}{ Surface and Compositional Properties } \\
\hline Geometric Albedo (\%) & $4.5 \pm 0.5$ & $4.4 \pm 0.2$ \\
\hline Normal Albedo Range (\%) & Undetermined & $3.5-\geq 15$ \\
\hline Thermal Inertia $\left(\mathrm{J} \mathrm{m}^{-2} \mathrm{~s}^{-0.5} \mathrm{~K}^{-1}\right)$ & $310 \pm 70$ & $350 \pm 20$ \\
\hline Average Particle Size (cm) & $<1 \mathrm{~cm}$ & TBD \\
\hline Largest Boulder (m) & $(10-20) \pm 7.5$ & Height: $30 \pm 3$, Length: $58 \pm 6$ \\
\hline$\#$ of Boulder $>10 \mathrm{~m}$ & Undetermined & $208 \pm 40$ \\
\hline CSFD ${ }^{* * *}$ slope (down to $\left.8 \mathrm{~m}\right)$ & Undetermined & $-2.9 \pm 0.3$ \\
\hline Average Surface Slope $\left(^{\circ}\right)$ & $15 \pm 2.4$ & $17 \pm 2$ \\
\hline Asteroid Spectral Type & B & B \\
\hline Closest Meteorite Analogs & $\mathrm{CI}$ and $\mathrm{CM}$ chondrites & $\mathrm{CM}$ chondrites \\
\hline
\end{tabular}


* COM/COF, center of mass/center of figure

*** Assuming uniform density

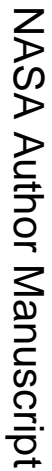

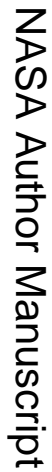

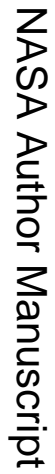

Nature. Author manuscript; available in PMC 2019 October 01. 